\title{
Kritik der Mandelbaumschen Veränderung der Wa.R.
}

\section{Von Arthur Mahlo,}

Oberarzt d. R. und Beratender Hygieniker einer Armee.

Störend wirken bei der Wa.R. oft die eigenhemmenden Eigen. schaften des Serums gegenüber dem Komplement. Von den Methoden, die angegeben worden sind, um die Eigenhemmung des" Serums auszuschalten, wollen wir hier nur zu der von Mandelbaum angegebenen Aenderung Stellung nehmen. Sie besteht darin, daß Serum nicht in konzentrierter Form bei $56^{\circ}$ inaktiviert wird, sondern in einer Mischung von 0,5 Serum und $2 \mathrm{ccm}$ physiologischer Kochsalzlösung. Dadurch sollen Eigenhemmungen so gut wie ausgeschaltet und die Reaktionsbreite der Wa.R. verbreitert werden.

Selter konnte die Ergebnisse Mandelbaums bestätigen.

Wir haben hier die Aendelung nach Mandelba um an etwa 300 Seren mit der Wa.R. verglichen; unsere Anwendungsweise der Wa.R. hielt sich streng an die während des Krieges gegebenen Vorschriften unter Berücksichtigung der von $v$. Ka uf mann gemachten Beobachtungen über die von der Kaiser-Wilhelms-Akademie gelieferten Extrakte. Besonderen Wert legten wir auf die Ablesung der Ambozeptoreinstellung mit der Lupe. Unsere Seren stammten alle von einer Geschlechtskrankenabteilung. "Sie lagerten bis zur Verwendung (zwei bis drei 'Tage) zentrifugiert mit dem Blutkuchen in dem Eisschrank, unterlagen somit alle einer gleichmäßigen Behandlung. Gemacht wurde die Reaktion mit je zwei Extrakten, und zwar mit den Extrakten 22, 23, 24 der Kaiser -Wilhelms - Akademie. Die Ablesung erfolgte sof ort nach Lösung der Serumkontrolle, nach 20 Minuten und nach einer stunde.

Gleichmäßig negativ reagierten 196

$$
\begin{array}{lll}
, \quad \text { positiv }, & 90 \\
, & \text { Eigenhemmungen } & \text { zeigten } 3
\end{array}
$$

Eigenhemmung bei Mandelbaum und nicht bei Wa.R. 3 , bei Wa.R. und nicht bei Mandelbaum 2

Folgende Fälle zeigten Verschiedenheit der Reaktion:

1 Fall reagierte nach Mandelbaum +++ , nach Wa.R. \pm

2 Fälle

2

Fall reagi"

,

ierte nach

Wa.R. +++ , nach Mandelbaum $\emptyset$

l " " " $\quad++, \quad, \quad$ ",$\quad$,

6 Fälle $, \quad, \quad, \quad \pm, \quad, \quad, \quad$

Nach unseren Erfahrungen ist also die Mandelbaum. sche Aenderung keine Verbesserung der Wa.R. Es kann zweckdienlich erscheinen, die MandeJbaumsche Aenderung bei Figenhemmung anzuwenden. Eine sichere Gewähr für das Verschwinden der Eigenhemmung bietet sie jedoch nicht. 